Dukes, who had a long association with the Fund, studied familial polyposis coli in the $1920 \mathrm{~s}$ and $1930 \mathrm{~s}$, and seems to have come close to putting his finger on the idea that the development of a cancer requires several distinct genetic events. In an inherited cancer the first event is already present through the germ line, which Dukes and his collaborator LockhartMummary did not perceive, and which was in fact suggested much later by A. G. Knudson working on retinoblastoma.

Tumour virology is an area in which the Fund has contributed signally to both of the branches involved - viruses as causes of cancer and viruses as means to understanding cancerous transformation of cells. William Gye, the Fund's third director, believed passionately in the tumour virus theory but it was not until a decade after his death that his belief was made manifest. Michael Stoker's appointment to the directorship in 1968 ushered in a decade of excellence in tumour virology, putting the Fund unmistakably at the forefront of international research.

Science, like pretty much everything else, is more interesting when its success or failure is seen in terms of the ambitions and weaknesses of those who pursue it. Is the history of a research organization more than the biographies of those who work for it? The rise and fall of scientific theories is dry stuff divorced from the rise and fall of those who create or espouse them. Poor James Murray, who became impaled on the discredited chronic irritation theory of cancer. And the life of his successor, William Gye, is the stuff of a rags to riches epic novel. Born in poverty, Gye left school at the age of 13 and worked as a stonemason and railway clerk, where he found time to study chemistry. Entering University College, Nottingham, he paid his examination fees by playing professional cricket. He read medicine at Edinburgh and later worked at the National Institute for Medical Research before becoming the director of ICRF. The previously esoteric and neglected viral theory of cancer gained greatly from his adoption of it.

It is not really surprising that much of the best part of Dr Austoker's history is 'cancer politics'. She deals adroitly with the dark days of the $1920 \mathrm{~s}$, when the Fund's great rival, the British Empire Cancer Campaign (later the Cancer Research Campaign), arrived to claim a share of what had until then been the Fund's territory; and with the attempt by Sir Walter Fletcher, secretary of the Medical Research Council, to establish the undisputed hegemony of the MRC in British medical research.

Why do we need books such as this? The answer is found in the words of Eric Larrabee:

The only thing wrong with scientists is that they don't understand science. They don't know where their own institutions came from, what forces shaped and are still shaping them and they are wedded to an anti-historical way of thinking which threatens to deter them from ever finding out ["Science and the Common Reader”, Commentary; June 1966].

Anything that tells scientists - and everyone else - about the origins of their national scientific institutions, how they work and how sometimes they don't, must be a good thing. When the account is as lucid, as scientifically well-informed and as thoroughly documented as this, it is a very good thing indeed.
It is therefore a pity that Dr Austoker was not allowed to finish her history. Her re-creation of the past should have been permitted to illuminate the Fund as it is today - we need to see it through an outsider's eye, and must always suspect the director of heroically justifying its existence. I cannot believe Dr Austoker did not do the research for the final part of the book. It ought to be published.

John Galloway is Head of Public Relations for the Cancer Research Campaign, 2 Carlton House Terrace, London SW1 5AR, UK. The opinions expressed in this review are his own.

\section{Physical interface}

\section{J. H. Mulvey}

Nuclear and Particle Physics Source Book. Editor-in-chief Sybil P. Parker. McGrawHill: 1988. Pp. 529. \$35.

WhAT is a "source book", and who needs one? McGraw-Hill published a series of ten of them in 1988 containing, as they say, "up-to-date and comprehensive coverage" of topics as diverse as acoustics, meteorology, communications and physical chemistry, "to answer the need for targeted information on scientific and technological questions". The volume on nuclear and particle physics contains about 150 entries ranging in length from paragraphs defining a word to minimonographs of over 20 pages. All are invited contributions from recognized authorities, including $\mathbf{J}$. D. Bjorken on quantum electrodynamics (QED), the quantum field theory of electromagnetism, Alan Bromley on nuclear molecules, Dick Dalitz on baryons and mesons, C. N. Yang on gauge theory and Glenn Seaborg on transuranic elements.

Most of the articles are excellent, as one would expect of the authors, and many who work in these fields would find the book well worth dipping into. Their interest could be caught by Chris Quigg's readable essay on quantum chromodynamics (QCD), the theory believed to describe the strong force imprisoning quarks in the proton and neutron; or perhaps by Walter Greiner's account of super-critical electrostatic fields. These intense fields, capable of breaking down the normal vacuum - empty of real particles - into a new vacuum where real particles can exist, may occur in the near neighbourhood of two highly charged nuclei meeting in collision; there are analogies in the QCD mechanism that are proposed to be responsible for quark confinement and, in the case of gravity, the emission of particles from the vicinity of a black hole as predicted by Hawking. Although articles published in Scientific American are frequently cited in the bibliographies, and many of the authors treat their topics at an equivalent level, some other entries make much greater demands on the reader's theoretical or technical understanding.

Such a book is not meant to be read from cover to cover, but doing so reveals more repetition than seems necessary. More seriously, there are some quite surprising omissions. There is no mention of nuclear magnetic resonance techniques as used in chemistry, biology and diagnostic medicine, yet NMR is one of the most powerful of the many tools passed on by physics to other sciences. In a book emphasizing the interface between nuclear and particle physics, it is odd that no place is found for the EMC (European muon collaboration) effect, dating from 1983 , which directly probes the quarkgluon composition of nuclear matter - as opposed to that of free nucleons; nor is there adequate treatment of the many examples of cross-fertilization between particle physics and cosmology. The section on particle detectors is especially disappointing, perhaps reflecting, more than other areas, the origin of the entries in an encyclopaedia which is now in its sixth edition and which is apparently not keeping up with new experimental techniques. Inadequate cross-referencing, and some poor choices of section titles, will hinder the non-professional - the topic of stellar energy sources is not indexed, for example, and one has to know enough already to look under "proton-proton chain" and "carbonnitrogen-oxygen cycles"

There are many meaty pieces in this hotch-potch of scientific nourishment but it would have benefited from tighter editing and better scientific guidance in its preparation. Whether such books are needed by the professional, given the wide range of up-to-date reviews available, is doubtful. But they do give an easily accessible overview of a wide range of topics, and students - and perhaps teachers - will find it useful to have them in the library for reference.

J. H. Mulvey is a Senior Research Officer in the Department of Nuclear Physics, University of Oxford, Keble Road, Oxford OXI 3RH, UK. 